要 旨：症例は41歳, 男性, 健康診断にて腹部超音波検査を行なったところ, 肝外門脈は描出 されず，肝門部および膵頭部に無エコーの脈管構造を多数認めた。 CT, MRIでも門脈本幹は描 出されず，蛇行した数秼状の脈管を認めた，門脈造影では門脈本幹は描出されず，著明に拡張 蛇行した求肝性の側副血行路を認めた。 また，下大静脈造影では㹂門部より尾側において大動 脈の左側を走行し，左腎静脈と合流後右側へ移動する左側下大静脈を認めた。 以上の所見から

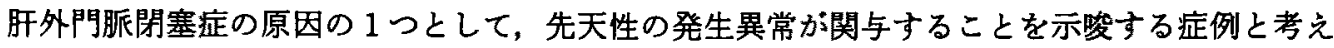
られた。

索引用語： 左側下大静脈 Cavernous transformation 肝外門脈閉塞症

はじめに

肝門部海綿状变化 (Cavernous transformation : CVT)は，肝外門脈が何らかの原因により閉塞された 場合に形成される求肝性の側副血行路が，海綿状血管 畽様の外観を呈するものである．今回我々は成人男性 に先天奇形の左側下大静脈を合併した CVTを経験し たので，CVTの成因に関して興味ある症例と考兄報 告する。

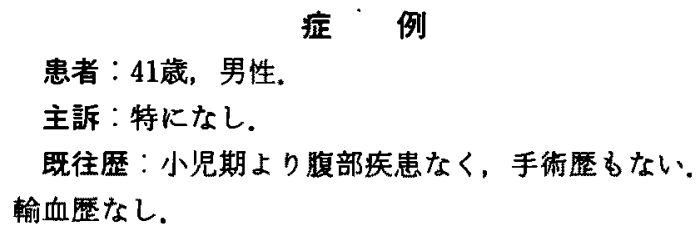

患者：41歳，男性.

主訴：特になし。

既往歴：小児期より腹部疾患なく，手術歴もない。 輸血歴なし。

家族歴：特記すべきことなし。

生活歴：䒜煙なし，领酒なし。

現病歴：平成 1 年 12 月 20 日職場の健康診断で腹部超

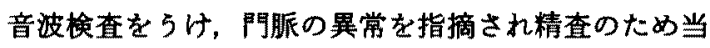
科入院となる。

入院時現症：身長 $167 \mathrm{~cm}$, 体重 $67 \mathrm{~kg}$, 脈拍 $66 /$ 分整, 血圧 $110 / 60$, 負血, 黄㡺なく，胸部には異常を認めな かった，腹部では肝脾腫は認めず，下駺浮嗹はなかっ た。皮庙には手掌紅斑，〈も状血管㣫を認めなかった。

入院時検査所見 (Table)：ICG 停滞率が $16.8 \%$ と軽 度上昇を認めたが，消失率は0.193と正常であった。そ

- 池田回生病院内科

**鳥取大学医学部第 2 内科

<受付日1991年1月16日>
Table Laboratory Data.

\begin{tabular}{|c|c|c|c|c|}
\hline \multicolumn{2}{|c|}{ Peripheral blood } & \multicolumn{2}{|c|}{ T-Chol } & $150 \mathrm{mg} / \mathrm{d} l$ \\
\hline WBC & $4,100 / \mathrm{mm}^{3}$ & \multicolumn{2}{|l|}{ TG } & $76 \mathrm{mg} / \mathrm{d} l$ \\
\hline $\mathrm{RBC}$ & $450 \times 10^{4} / \mathrm{mm}^{3}$ & \multicolumn{2}{|c|}{ BUN } & $8 \mathrm{mg} / \mathrm{d} l$ \\
\hline $\mathrm{Hb}$ & $15.2 \mathrm{~g} / \mathrm{d} l$ & \multicolumn{2}{|l|}{$\mathrm{Cr}$} & $0.8 \mathrm{mg} / \mathrm{d} l$ \\
\hline $\mathrm{Ht}$ & $40.8 \%$ & \multicolumn{2}{|l|}{ UA } & $4.7 \mathrm{mg} / \mathrm{d} l$ \\
\hline Plt & $22.5 \times 10^{4} / \mathrm{mm}^{3}$ & \multicolumn{2}{|l|}{$\mathrm{TP}$} & $6.0 \mathrm{~g} / \mathrm{d} l$ \\
\hline \multicolumn{2}{|c|}{ Coagulation Test } & \multicolumn{2}{|c|}{ Alb } & $66.6 \%$ \\
\hline PT & $83 \%$ & \multicolumn{2}{|l|}{$\alpha_{1}$} & $4.0 \%$ \\
\hline APTT & $31.1 \mathrm{sec}$ & \multicolumn{2}{|l|}{$\alpha_{2}$} & $8.9 \%$ \\
\hline \multicolumn{2}{|c|}{ Biochemistry } & \multicolumn{2}{|l|}{$\hat{\theta}$} & $9.1 \%$ \\
\hline $\mathrm{T} \cdot \mathrm{Bil}$ & $0.7 \mathrm{mg} / \mathrm{d} l$ & \multicolumn{2}{|l|}{$\gamma$} & $11.3 \%$ \\
\hline D-Bil & $0.4 \mathrm{mg} / \mathrm{d} l$ & \multicolumn{2}{|c|}{ ZTT } & $4.9 \mathrm{U}$ \\
\hline GOT & $16 \mathrm{U}$ & \multicolumn{2}{|c|}{ TTT } & $0.3 \mathrm{U}$ \\
\hline GPT & $11 \mathrm{U}$ & \multirow[t]{2}{*}{ ICG } & $\mathrm{R}_{15}$ & $16.8 \%$ \\
\hline LDH & $247 \mathrm{U}$ & & K & 0.193 \\
\hline ALP & $4.5 \mathrm{~K}-\mathrm{AU}$ & \multicolumn{3}{|c|}{ Serological finding } \\
\hline LAP & 111 G-RU & \multicolumn{2}{|c|}{ HBS-Ag } & $(-)$ \\
\hline r-GTP & $8 \mathrm{U} / l$ & \multicolumn{2}{|c|}{ HBS-Ab } & $(-)$ \\
\hline $\mathrm{ChE}$ & $8.3 \mu \mathrm{mol}$ & \multirow{2}{*}{\multicolumn{2}{|c|}{$\mathrm{HCV} \cdot \mathrm{Ab}$}} & $(-)$ \\
\hline TBA & $1.8 \mathrm{nmol} / \mathrm{m} l$ & & & \\
\hline
\end{tabular}

の他，肝・堅機能に異常は認めなかった。

腹部超音波検查 (US) 所見 (Fig. 1)：右助弓下走査 で門脈右枝および左枝横行部は 1 本の管腔としては描 出されず，数珠状の脈管が認められた（Fig，1A）。 心 窝部横走查では膵頭部に屈曲蛇行した脈管を認めた (Fig. 1B).

腹部 CT 所見 (Fig. 2)：造影 CTにて門脈右枝およ び左枝は不明瞕な脈管として描出され(Fig.2A)，門脈 


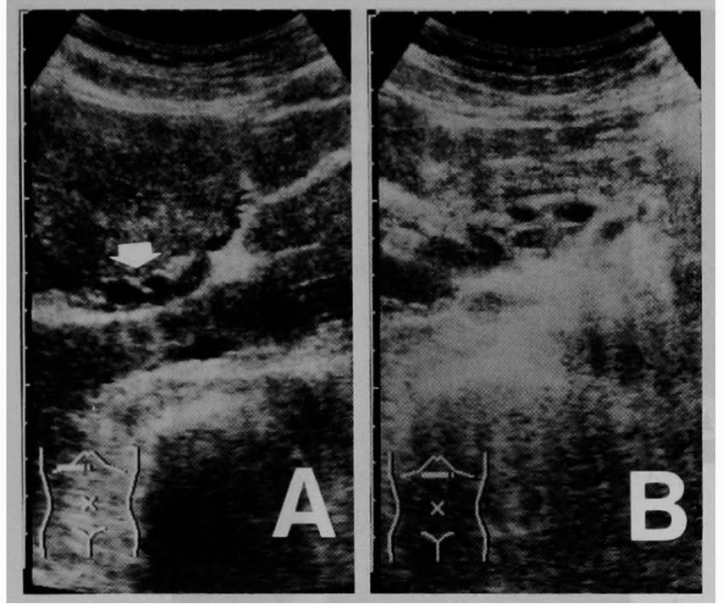

Fig. 1 Ultrasonographic findings

A. Tortuous vessels (arrow) replacing the portal trunk are seen at the porta hepatis.

B. Multiple anechoic tubular structures are seen at the head of the pancreas.
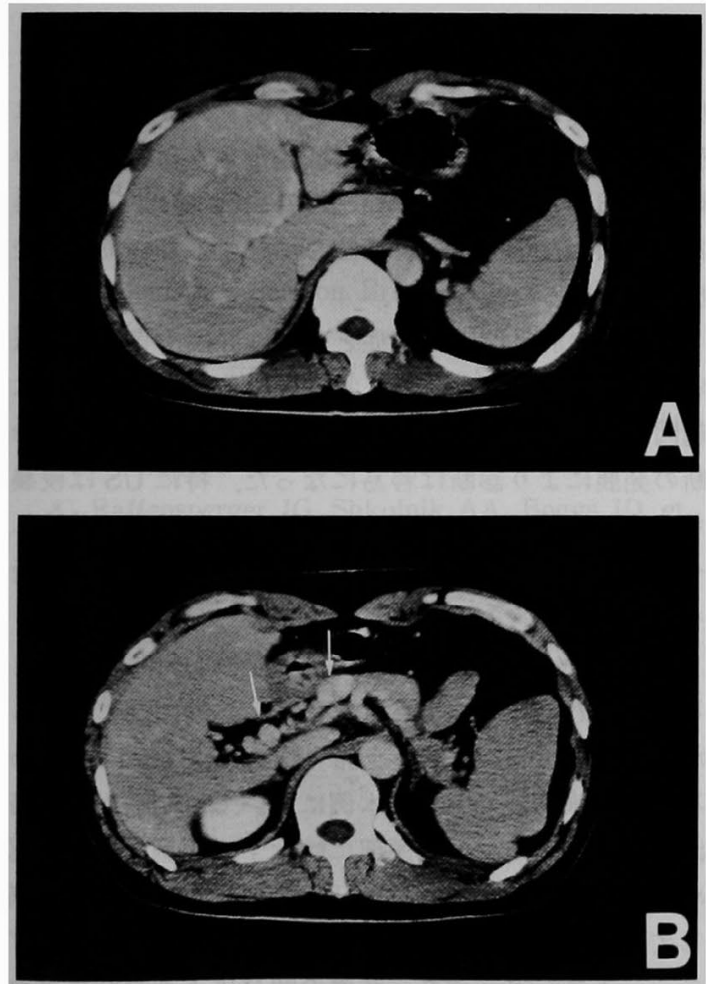

Fig. 2 Enhanced CT

Main portal vein cannot be seen and meandering vessels (arrows) are seen at the porta hepatis and the head of the pancreas.

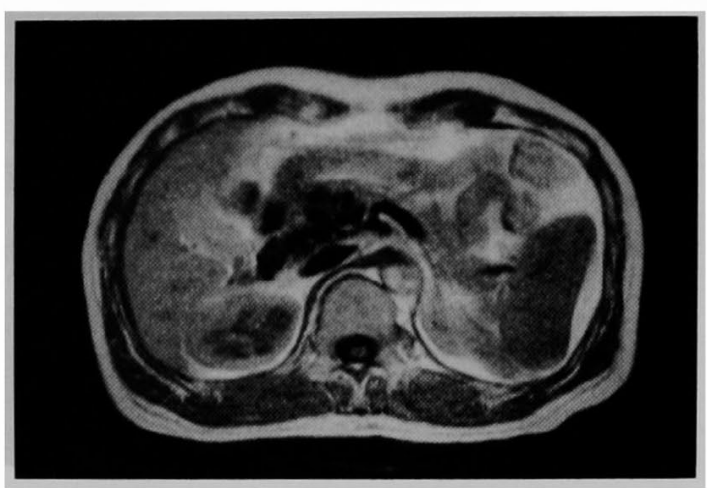

Fig. $3 \mathrm{MR}$ imaging ( $\mathrm{T}_{1}$-weighted images) Multiple tortuous vessels are more clearly delineated as low intensity structures than those in CT.

本幹は描出されず蛇行した数珠状の脈管が認められ た.また, 軽度の脾腫を認めた（Fig. 2B).

MR imaging 所見 (Fig. 3)：膵頭部および肝門部 に蛇行した脈管群を明瞭に認めた。

血管造影所見（Fig. 4)：上腸間膜動脈造影門脈相 (Fig. 4A) および脾動脈造影静脈相では門脈本幹は描 出されず，著明に払張蛇行した求肝性の側副血行路 (CVT)を認めたか;，遠肝性の側副血行路(食道静脈瘤 等)は認めなかった。 また，下大静脈造影 (Fig. 4B) では下大静脈は腎門部より尾側で大動脈の左側を走行 し，左腎静脈と合流後，大動脈を乗り越えて右側へ移 行していた。

上部消化管内視鏡検查：食道・胃静脈瘤は認めな かった。

内視鏡的逆行性胆道膵管造影：膵および胆道系には 異常を認めなかった。

肝生検所見：門脈域・小葉内に異常は認めず，正常 肝組織であった。

\section{考察}

CVT は肝外門脈が何らかの原因によって閉塞後, 二次的に門脈周囲の血管叢が拡張し, 求肝性の側副血 行路が形成されたものである。その原因に関してはお おむね以下のものが考えられている゙.

1) 先天性門脈形成異常

2) 新生時期の門脈炎(腈炎, 腹膜炎, 敗血症の波及 等)

3) 後天性門脈閉塞(悪性腫湟の浸潤, 腹腔内荗器の 资症, 腹部外傷, 腹部手術, 血液凝固能の元進する全 身疾患等） 
$28: 784$


Fig. 4 Angiography

A. Portography through superior mesenteric artery shows numerous hepatopetal collateral channels.

B. Cavography reveals that inferior vena cava runs to the left of the aorta and it shifts from the left to the right at the level of the left renal hilum.


らかの感染症の既往を認めているが原因不明も50例と

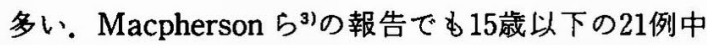
18例は明らかな原因を認めていないことから，原因不 明の大部分は先天異常によるものと考えている.他方, Parker ら"は先天奇形を合併した肝外門脈閉塞症む 合併しない症例む聞脈の組織所見には差異を認めな かったと報告しており，先天的要因の存在を直接的に 証明した報告はない。しかし, Odievre ら5゙は原因不明 の小児肝外門脈閉塞患者30例中12例に何らかの先天異 常の合併がみられたのに対し，臍炎あるいは臍静脈力 テーテル摷入後に発生したものでは17例中 2 例のみに 先天異常がみられたにすぎないと報告しており，発生 学上の巽常かＣＶTT の成立に関与している可能性が高 い.

本例は肝外門脈閉塞症に左側下大静脈といら先天異 常を合併していた，左側下大静脈は発生学的に本来残 るべき右上主静脈（right supracardinal vein）にか わって左上主静脈 (left supracardinal vein) が残存し たため，腎静脈よりも尾側において下大静脈が大動脈 の左側を走行するものである6)，左側下大静脈の頻度 は0.2 0.5\%之稀な疾患である6,7)病的意義は少な い. 下大静脈に何らかの奇形を合併した肝外門脈閉塞
症は 4 例報告されているが5,8\}，左側下大静脈を伴った 症例は筆者の渉椫した限りでは報告をみない，本例の 結果から肝外門脈閉塞症の一部の症例は発生学上の異 常が原因となっている可能性を示唆するもので, 今後 症例の蓄積が必要である。

後天性の肝外門脈閉塞症としては肝癌や胃癌の門脈 内浸潤9,10), 膵炎の波及 ${ }^{11}$, 骨䯣線維症等の血液疾患に 起因するもの 断の発展により診断は容易になった。特にUSは侵襲 むなく, 検診のスクリーニング検査として広く普及し つつあるので, 今後本例のょらに偶然発見される機会 もふえてくるるのと思われる。

Kauzlaric ${ }^{13)}$ Prider ら ${ }^{14)}$ は本症の US 像の特徵之 して, 肝外門脈が描出されないこと, 肝門部に蛇行し た多くの脈管や，高エコー帯 (Diamond sign) を認め ることを報告している，本例においても門脈本幹は描 出されず，肝門部・膵頭部に驼行する側副血行路を認 めており,これらの所見は肝外門脈閉塞症の診断に際 して有力な手がかりとなろう。近年, 超音波ドップ ラー。カラードップラ一装置の開発により求肝性の血 流を検出することも可能となり ${ }^{15)}$, さらにdynamic CT MRI は蛇行した側副血行路を明瞭に描出する ことができる. 特に MRI は血管系が管状の無信号構 
造として描出され，撮像断面を自由に選抧できること から診断能は高いものと理解される。本症例では最終 的には血管造影により確定診断を行なったが, 肝外門 脈閉塞症はUS, CT, MRI などの非侵襲的検査法で十 分診断可能と考えられる.

$$
\text { 文献 }
$$

1）杉浦光雄, 島 文夫, 二川浚二, 他：小巟門眽圧え元 進庭 手術 32:251-263, 1978

2) Webb LJ, Sherlock S: The aetiology, presentation and natural history of extra-hepatic portal venous obstruction. Quart J Med 192: 627 $-639,1979$

3) Macpherson AIS : Portal hypertension due to extrahepatic portal venous obstruction-A review of 40 cases-. J Roy Coll Surg Edinb 29 : 4-10, 1984

4) Parker RA, Seal RME: Cavernous transformation of the portal vein. J Path Bact 70:97 $-103,1955$

5) Odievre M, Pige G, Alagille D: Congenital abnormalities associated with extrahepatic portal hypertension. Arch Dis Child 52 : 383-385, 1977

6) Chuang VP, Mena CE, Hoskins PA : Congenital anomalies of the inferior vena cava. Review of embryogenesis and presentation of a simplified classification. Brit J Radiol 47 : 206-213, 1974

7) Pillari G, Wind ES, Wiener SL, et al: Left inferior vena cava. Amer J Roentgenol $130: 366$ $-367,1978$

8) Raffensperger JG, Shkolnik AA, Boggs JD, et al: Portal hypertension in children. Arch Surg 105 : 249-254, 1972

9) Ohnishi K, Okuda $K$, Ohtsuki $T$, et al: Formation of hilar collaterals or cavernous transformation after portal vein obstruction by hepatocellular carcinoma-Observations in ten patients-. Gastroenterology $87: 1150-1153$, 1984

10）有賀明子，渡边佰家，桧山義明，他：胃癌に伴5門 脈内腫煌塞栓に上り cavernous transformation を呈した 1 例。日消誌 83:2243-2247, 1986

11) Longstreth GF, Newcomer AD, Green PA: Extrahepatic portal hypertention caused by chronic pancreatitis. Ann Intern Med 75: 903 $-908,1971$

12）小川兹彦，山崎義隹与，羽場利博，他：肝外門脈閉 塞定を伴い胆管周囲に著明な cavernous trans-

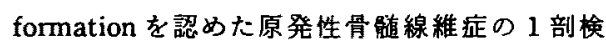
例. 日消誌 $84: 108-112,1987$

13) Kauzlaric D, Petrovic M, Barmeir E: Sonography of cavernous transformation of the portal vein. Amer J Roentgenol 142 : 383-384, 1984

14) Frider B, Marin AM, Goldberg A : Ultrasonographic diagnosis of portal vein cavernous transformation in children. $\mathrm{J}$ Ultrasound Med $8: 445-449,1989$

15) Weltin G, Taylor KJW, Carter AR, et al : Duplex Doppler: Identification of cavernous transformation of the portal vein. Amer J Roentgenol 144 : 999-1001, 1985 


\title{
A case of extrahepatic portal vein obstraction (Cavernous transformation) with left inferior vena cava
}

\author{
Masahiko KoDA, Yoji MrYoshi* and Hironaka KAWASAKI**
}

We report a case of extrahepatic portal vein obstraction (EHO), observed cavernous transformation in the porta hepatis, with left inferior vena cava. The patient was a 41 -year-old man and was admitted to our hospital because of checking up his health. Ultrasonography. Computed tomography and MR imaging revealed multiple tortuous vessels at the porta hepatis and the head of the pancreas replacing main portal vein. Portography showed numerous hepatopetal collateral vessels around the obstructed portal vein, while cavography demonstrated left inferior vena cava. EHO with anomalous inferior vena cava is very rare condition. These data demonstrate that some cases with EHO like this case are congenital in origin.

* Department of Medicine, Ikeda Kaisei Hospital (Osaka)

** The Second Department of Medicine, Tottori University, School of Medicine (Yonago) 